\title{
Study on bone health in postmenopausal women at a tertiary care hospital
}

\author{
Nidhi Gupta ${ }^{1, *}$, Pallavi ${ }^{2}$, Renuka Sinha ${ }^{3}$, Farhat Mazhari ${ }^{4}$ \\ ${ }^{\mathbf{1}}$ Assistant Professor, ${ }^{\mathbf{2}, \mathbf{4}}$ Senior Resident, ${ }^{3}$ Professor and HOD, Dept. of Obstetrics and Gynaecology, ${ }^{\mathbf{1 , 2}, \mathbf{4}} \mathrm{HIMSR}$, New Delhi, \\ ${ }^{3}$ Rama Medical College, Ghaziabad, Uttar Pradesh, India
}

*Corresponding Author:

Email: drnidhigupta19@gmail.com

\begin{abstract}
Objectives: 1) To find the prevalence of musculoskeletal symptoms after menopause. 2) To evaluate the densitometry findings in menopausal patients presenting with musculoskeletal symptoms. 3) To know the effect of duration of menopause on densitometry findings.

Materials and Methods: This study is a prospective study conducted in the specialty outpatient department of Safdarjung hospital over a period of one year. 200 postmenopausal women with musculoskeletal symptoms during this period were included after fulfilling the inclusion criterion and were divided into two groups based on duration of menopause.

Results: The musculoskeletal complaints were assessed as body ache, joint pain, numbness and tingling which were not statistically significantly different in two groups. 32 (29.9\%) women who were more than 5 years post-menopausal (group B) were osteoporotic compared to 21 (22.6\%) of women who were less than 5 years post-menopausal (group A). This data is not statistically significant.

Conclusion: There is a need to improve awareness among the menopausal women and healthcare provider on menopausal symptoms and variety of intervention ranging from lifestyle modifications to pharmacological interventions.
\end{abstract}

Keywords: Musculoskeletal Symptoms, Menopause, Osteoporosis, Osteopenia.

\section{Introduction}

International menopause society defined menopause as the permanent cessation of menstruation resulting from the loss of ovarian follicular activity. ${ }^{1}$ Menopausal women are having varied symptoms due to the cessation of ovarian estrogen production resulting in vasomotor symptoms, musculoskeletal changes, urogenital atrophy, cognitive changes, sleep disturbance, sexual dysfunction and psychological problems. Musculoskeletal complaints are much common in post-menopausal women because the natural protection to osteoporosis is lost leaving women prone to fractures with minor trauma. ${ }^{2}$

Osteopenia and osteoporosis result from a reduction in the quantity of bone mass and the deterioration of bone microstructure, leading to a general loss in bone strength. ${ }^{3}$ With the onset of menopause, rapid bone loss occurs which is believed to average approximately $2-3 \%$ over the following 5-10 years of menopause. ${ }^{4}$ The prevalence of osteoporosis increases with age for all sites, and by World Health Organization (WHO) definition, up to $70 \%$ of women over the age 80 years have osteoporosis. ${ }^{4}$ In India, it is estimated that more than 61 million people have osteoporosis; of these, $80 \%$ patients are females. ${ }^{5}$

It is important to gain a better understanding of diversity and complexity of menopausal changes to optimize and maximize management options. In this context the objective of our study was to find prevalence of various musculoskeletal complaints in menopausal women, to evaluate the densitometry findings in menopausal patients presenting with musculoskeletal symptoms and degree of osteopenia and osteoporosis with duration of menopause.

\section{Materials and Methods}

This study is a prospective observational study conducted in the menopausal specialty clinic of Safdarjung hospital over a period of one year. All the women who attained menopause either naturally or surgically who presented first time to the clinic for any complaints were evaluated for the musculoskeletal symptoms with the help of pre-designed questionnaire.

Based on the duration of menopause, the women included in the study were divided in to two groups. Group A constitute the women in which duration of menopause was 1-5 years and group B constitute the women with duration of menopause 5-10 years.

The questionnaire contained questions about their demographic data including age, age of menopause, weight, height, number of pregnancies and births, route of delivery, marital status, any addiction like smoking or alcohol, personal details like sleep pattern or dietary habits, regular exercise, educational level and income via open-ended questions. The musculoskeletal complaints evaluated were body ache, joint pain, tingling or numbness.

Women who had not elapsed a time of 1 year from the last menstrual period or women who were more than 10 years post-menopausal, with pre-existing complaints before menopause and those with medical conditions which can affect bone mass like hyperthyroidism, hyperparathyroidism drugs, arthritis, diabetes or neurological problems which can affect bone mass were excluded from the study. The women of both group underwent DEXA (dual-energy x-ray absorptiometry) scan to determine $\mathrm{T}$ score and the women of both groups were evaluated to be normal/osteopenic or osteoporotic. T score compares a 
woman's bone density compared to a healthy young woman. $\mathrm{T}$ score of -1 to +1 is taken as normal, $\mathrm{T}$ score of -2.5 to -1 is taken as osteopenia and below 2.5 as osteoporosis according to the WHO-BMD diagnostic categories. ${ }^{5}$ Data was analyzed by standard statistical analytical tests.

\section{Results}

This is a prospective observational study in which all the new registered cases of menopausal women with varied duration of menopause were screened. It constituted the 320 women who came to speciality menopausal clinic for any complaints after menopause. Among these women, 200 postmenopausal females were having musculoskeletal complaints and were included in the study making the prevalence of musculoskeletal symptoms in our study was $62.5 \%$.

Among 200 women included in the study, 38 $(19 \%)$ were in age group 45-55 years, $86(43 \%)$ were in 56-65 years age group and rest of the females that is 76 $(38 \%)$ were $>65$ years age. Based on duration of menopause, two groups were made as shown in Table 1. Women who were having less than 5 years of menopause, were included in group $\mathrm{A}$, which constituted $93(46.5 \%)$ of the total women. The mean age in this group was 52.2 years. Group B which included 5-10 years post-menopausal women had 107 participants, constituting $53.5 \%$ of the total participants. The mean age in this group was 60.8 years.

Table 1: Duration \& nature of menopause

\begin{tabular}{|l|c|c|c|}
\hline $\begin{array}{c}\text { Duration of } \\
\text { menopause }\end{array}$ & $\begin{array}{c}\text { Natural Menopause } \\
\text { (Number) }\end{array}$ & $\begin{array}{c}\text { Surgical Menopause } \\
\text { (Number) }\end{array}$ & $\begin{array}{c}\text { Total } \\
\text { Number }(\% \text { age })\end{array}$ \\
\hline $1-5$ years & 85 & 8 & $93(46.5 \%)$ \\
\hline $5-10$ years & 104 & 3 & $107(53.5 \%)$ \\
\hline
\end{tabular}

The musculoskeletal complaints were assessed as body ache, joint pain, numbness and tingling. Joint pain was reported by every $9^{\text {th }}$ woman of group A $(85$, $91.3 \%)$, while only 67 (62.6\%) women in group B complained of joint pain. Around two third women in either group had complaint of body ache: either generalized or localized $(64,68.8 \%$ in group A \& 69 , $64.4 \%$ in group B).

Table 2: Musculoskeletal symptoms ${ }^{\circ}$

${ }^{\circ}$ multiple answers

\begin{tabular}{|c|c|c|c|}
\hline $\begin{array}{c}\begin{array}{c}\text { Musculo-skeletal } \\
\text { symptoms }\end{array} \\
\end{array}$ & $\begin{array}{c}\text { Group } \mathbf{A} \\
\text { Number (\% age) }\end{array}$ & $\begin{array}{c}\text { Group B } \\
\text { Number (\% age) }\end{array}$ & P value \\
\hline Body Ache & $64(68.8)$ & $69(64.4)$ & \multirow{4}{*}{$\begin{array}{c}0.28 \text { (Not } \\
\text { significant) }\end{array}$} \\
\hline Joint Pains & $85(91.3)$ & $67(62.6)$ & \\
\hline Tingling & $13(14)$ & $19(17.7)$ & \\
\hline Numbness & $9(9.7)$ & $12(10.2)$ & \\
\hline
\end{tabular}

Numbness was least common musculoskeletal complaint in either group, a little more common in group B $(9,9.7 \%$ in group A compared to $12,10.2 \%$ in group B) although the difference was not statistically significant. (Table 2)

The results of DEXA scan show that 24(25.8\%) of women of group A and only $22(20.6 \%)$ women of group B lie in normal range. Half the women of either group had reduced bone density compared to normal but not low enough to be categorized as osteoporosis, and were included in osteopenic group $(48,51.6 \%$ of group A and 53, 49.5\% of group B). 32 (29.9\%) women who were more than 5 years post-menopausal (group B) were osteoporotic compared to $21(22.6 \%)$ of women who were less than 5 years post-menopausal (group A). This data is not statistically significant as shown in Table 3 .

Table 3: DEXA scan

\begin{tabular}{|l|c|c|c|}
\hline \multicolumn{1}{|c|}{ DEXA scan } & $\begin{array}{c}\text { Group A } \\
\text { Number }(\boldsymbol{\%} \text { age })\end{array}$ & $\begin{array}{c}\text { Group B } \\
\text { Number }(\boldsymbol{\%} \text { age })\end{array}$ & \multirow{2}{*}{ P value } \\
\hline Normal & $24(25.8)$ & $22(20.6)$ & $\begin{array}{c}0.43(\text { Not } \\
\text { significant) }\end{array}$ \\
\hline Osteopenia & $48(51.6)$ & $53(49.5)$ & \\
\hline Osteoporosis & $21(22.5)$ & $32(29.9)$ & \\
\hline
\end{tabular}

In our study it is seen that joint pain is a very frequent complaint in first 5 years of menopausal life. More than three-fourth post-menopausal women have reduced bone density and percentage of women belonging to osteoporotic range increases with years of menopause. 


\section{Discussion}

With the advent of modern medicine and increased life expectancy, many women are likely to live for more than two decades beyond menopause, in an estrogen deficient state. ${ }^{6}$ Across the world, there is a considerable variation among women regarding the age of attaining menopause and the manifestation of menopausal signs and symptoms. ${ }^{7}$ In 1990, about 25 million women worldwide reached menopause; this number is expected to double by the late 2020s. 2 About 130 million Indian women are expected to live beyond menopause by $2015 .{ }^{8}$

The prevalence of musculoskeletal complaints in Indian studies varies. It was found to be $53.3 \%$ in a study by Sagar et al. ${ }^{9}$ A secondary analysis by Mirca et al showed a baseline prevalence of $33 \%$ in Italian postmenopausal women. ${ }^{10} \mathrm{~A}$ study by Ramalingam et al in 2015 found the prevalence to be $48.4 \%$ among Indian women with 5 years duration of menopause. ${ }^{11}$

In Bairy et al's study, $67 \%$ women had muscle and joint pain and 59\% had low back ache. ${ }^{12}$ Shah, et al done a study in Mumbai, Muscle and joint pains was present in $37.4 \%$ and fatigue was there in $35.6 \%$ study subjects. Lu, et al (2007) conducted a cross-sectional survey in Australia among 197 Arabic women aged 45-65 years. Out of 29 symptoms, the most frequent symptom reported was "feeling tired or worn out" $(86 \%)$, followed by "aching in muscles and joints" $(85 \%){ }^{14}$

According to a study between 1990 and 2012 including 99,399 women from Austria who underwent BMD (bone mineral density) testing, 52.5\% showed normal, $34.0 \%$ osteopenic and $13.5 \%$ osteoporotic BMD. Their study also showed that $38 \%$ of osteoporotic and $33 \%$ of osteopenia in women had 1 or more fracture at presentation. In pre-menopausal Dutch women, the prevalence of osteopenia was $27.3 \%$, and $4.1 \%$ of the women were osteoporotic; and in Canadian women, the prevalence of osteoporosis was $20 \%{ }^{15}$

Compared to the Western World, the prevalence of osteopenia and osteoporosis is much higher in our and other Indian studies, reflecting poor overall health of menopausal women and women in general in India. ${ }^{6,8}$ The prevalence of low BMD (osteopenia and osteoporosis) is $77 \%$ in our study $(50.5 \%$ with osteopenia and $26.5 \%$ with osteoporosis).

Sharma et al found in their study that the incidence of osteoporosis was $(20.25 \%)$ and osteopenia $(36.79 \%)$ with maximum number of both osteoporosis and osteopenic women recorded in the age group of (55-64 years). After the age of 65 years, there was an almost $100 \%$ incidence of either osteopenia or osteoporosis, indicating that it increases with age and in postmenopausal period, thereby suggesting lack of estrogenic activity might be responsible for this increasing trend. ${ }^{16}$

The US preventive services task force recommends routine screening for osteoporosis in women over 65 years. In India we need to carry out further studies on whether we need to consider screening at an earlier age and to study osteoporosis in males. ${ }^{17}$

\section{Conclusion}

There is a need to increase awareness among the menopausal women and healthcare provider on menopausal symptoms and variety of intervention ranging from lifestyle modifications to pharmacological interventions. Healthcare providers should practice an evidence-based management in offering the best management for these women. The hope to see women embracing menopause gracefully should be upheld by everyone, rather than leaving them suffering in silence.

\section{References}

1. Utian WH, "The International Menopause Society menopause-related terminology definitions" Climacteric (1999) 2(4), 284-6.

2. Mishra N, Mishra VN, Devanshi, "Exercise beyond menopause: Dos and don'ts" J Midlife Health (2011)2,51-6.

3. Swedish Council on Health Technology Assessment (SBU): SBU Systematic Review Summaries [Internet]. Osteoporosis - Prevention, Diagnosis and Treatment: A Systematic Review 2003.

4. Aggarwal N, Raveendran A, Khandelwal N, "Prevalence and related risk factors of osteoporosis in peri- and postmenopausal Indian women" journal of midlife health (2011) 2 (2),81-5.

5. World Health Organization, "Assessment of fracture risk and its application to screening for postmenopausal osteoporosis. Report of a WHO Study Group" World Health Organ Tech Rep Ser (1994) 843,1-129.

6. Singh A, Pradhan SK, "Menopausal symptoms of postmenopausal women in a rural community of Delhi, India: A cross sectional study" J Mid-life Health (2014) 5,62-7.

7. R Marahatta, "Study of menopausal symptoms among peri and postmenopausal women attending NMCTH" Nepal Med Coll J (2012) 14(3),251-55.

8. Kaulagekar A, "Age of menopause and menopausal symptoms among urban women in Pune, Maharashtra" J Obstet Gynecol India (2011) 61,323-6.

9. Borker SA, Venugopalan PP, Bhat SN, "Study of menopausal symptoms, and perceptions about menopause among women at a rural community in Kerala" J Mid-life Health (2013) 4(3), 182-7.

10. Marini M, Bendinelli B, Assedi m et al, "Low back pain in healthy postmenopausal women and the effect of physical activity: A secondary analysis in a randomized trial" PLOS ONE https://doi.org/10.1371/journal.pone.0177370 May 10, 2017.

11. Kolisetty R, Jyothi NU, "Study of Symptoms in Postmenopausal Women: A Hospital Based Study" The International Journal of Indian Psychology (2015) 3(1), 87-91.

12. Bairy L, Shalini A, Bhat P, Bhat R, "Prevalence of menopausal symptoms and quality of life after menopause in women from South India" Aust N Z J Obstet Gynaecol (2009) 49,106-9.

13. Shah R, Kalgutkar S, Savardekar L, Chilang S, Iddya U, "Menopausal symptoms in urban Indian women" Obstet and Gynecol Today (2004) 11, 667-70. 
14. Lu J, Liu J, Eden J, “The experience of menopausal symptoms by Arabic women in Sydney" Climacteric (2007) 10, 72-9.

15. Boschitsch EP, Durchschlag E, Dimai HP, “Age-related prevalence of osteoporosis and fragility fractures: realworld data from an Austrian Menopause and

Osteoporosis Clinic" Climacteric (2017) 20 (2), 157-163.

16. Sharma S, Tandon VR, Mahajan A, Kour A, Kumar D, "Preliminary screening of osteoporosis and osteopenia in urban women from Jammu using calcaneal QUS" Indian J Med Sci (2006) 60,183-9.

17. Summary of recommendations screening for osteoporosis, 17. Jan 2011 US Preventive Services Task Force (USPTF) http/ www. US Preventive Services Task Force.org/usptf. 